University of Wollongong

Research Online

SMART Infrastructure Facility - Papers

Faculty of Engineering and Information

Sciences

2017

Using complex fuzzy sets for strategic cost evaluation in supply chain downstream

Jun Ma

University of Wollongong, jma@uow.edu.au

Lipeng Feng

University of Wollongong, Ipfeng@uow.edu.au

Jie Yang

University of Wollongong, jiey@uow.edu.au

Follow this and additional works at: https://ro.uow.edu.au/smartpapers

Part of the Engineering Commons, and the Physical Sciences and Mathematics Commons

Research Online is the open access institutional repository for the University of Wollongong. For further information contact the UOW Library: research-pubs@uow.edu.au 


\title{
Using complex fuzzy sets for strategic cost evaluation in supply chain downstream
}

\author{
Abstract \\ Cross-border E-commerce has grown exponentially in the past decade. To gain global competitivity in \\ product-convergent markets, China's over 200 thousands cross-border E-commerce businesses have \\ focused more on the service and cost of supply chain downstream. Therefore, selecting appropriate cost \\ control strategy has marked impact on them. In this study, we evaluated three strategic cost control \\ measures according to 10 evaluation criteria by using a complex fuzzy set based model, named C- \\ COPRAS. The C-COPRAS model is an extension of the COmplex PRoportion ASessment (COPRAS) \\ method. This model uses complex fuzzy set to tackle uncertainty and temporal features in given \\ evaluation context. We then apply this model to a case study of helping a Chinese E-commerce business \\ to select strategic cost control measure on supply chain downstream.

\section{Disciplines} \\ Engineering | Physical Sciences and Mathematics

\section{Publication Details} \\ Ma, J., Feng, L. \& Yang, J. (2017). Using complex fuzzy sets for strategic cost evaluation in supply chain \\ downstream. 2017 IEEE International Conference on Fuzzy Systems (FUZZ-IEEE) (pp. 440-445). United \\ States: IEEE.
}




\title{
Using Complex Fuzzy Sets for Strategic Cost Evaluation in Supply Chain Downstream
}

\author{
Jun $\mathrm{Ma}^{*}$, Lipeng Feng* ${ }^{* \dagger}$, Jie Yang* \\ *SMART Infrastructure Facility, Faculty of Engineering and Information Sciences, University of Wollongong \\ Northfields Ave, Wollongong, NSW 2522, Australia \\ ${ }^{\dagger}$ School of Economics Management, Chongqing University of Arts and Sciences \\ Yongchuan, Chongqing 402160, China \\ Email: \{jma, jiey, lpfeng\}@uow.edu.au
}

\begin{abstract}
Cross-border E-commerce has grown exponentially in the past decade. To gain global competitivity in productconvergent markets, China's over 200 thousands cross-border Ecommerce businesses have focused more on the service and cost of supply chain downstream. Therefore, selecting appropriate cost control strategy has marked impact on them. In this study, we evaluated three strategic cost control measures according to 10 evaluation criteria by using a complex fuzzy set based model, named C-COPRAS. The C-COPRAS model is an extension of the COmplex PRoportion ASessment (COPRAS) method. This model uses complex fuzzy set to tackle uncertainty and temporal features in given evaluation context. We then apply this model to a case study of helping a Chinese E-commerce business to select strategic cost control measure on supply chain downstream.
\end{abstract}

\section{INTRODUCTION}

In recent years, cross-border E-commerce arose and has become a burgeoning model of E-commerce. According to Accenture [1], in 2020 the global cross-border E-commerce market will balloon in size to \$1 trillion and more than 900 million people will be online consumers. By then, China will become the largest cross-border market with the transaction volume of imported goods purchased online reaching $\$ 245$ billion. One of the most important reasons for the dramatic development on it is that cross-border E-commerce business along the supply chain can lead to big cost savings [2].

Because of the significant impact of cost on cross-border E-commerce business, the importance of measuring the cost control has been discussed and many cost control studies have been performed by using different criteria [3] such as quality, time and flexibility. As the pace of market globalization quickens, the number of criteria to be considered will increase [4]. With criteria increasing, the chance of uncertain and temporal criteria appearing simultaneously will be greater. Therefore, using a method which can evaluate simultaneously uncertain and temporal criteria is a must. The complex fuzzy set (CFS) is a newly-established tools for handling both uncertain and temporal features. In this study, we extend the COmplex PRoportion ASessment (COPRAS) method by assigning CFS as assessment to evaluate supply chain downstream strategic cost control on cross-border E-commerce. This new method offers a more flexible way to solve evaluating problems in the real-world.
The reminder of the paper is organized as follows. Section II overviews basic concepts of complex fuzzy sets and its applications. Section III discusses ranking and aggregation based on CFSs. Section IV overviews strategic cost control measures in supply chain downstream and discusses the selection of criteria in strategic cost control. Section $\mathrm{V}$ presents an extended COPRAS method, C-COPRAS. Section VI focuses on the application of the C-COPRAS method on a cross-border E-commerce. Finally, Section VII presents the conclusion and directions for further steps of this study.

\section{COMPlEX FUZZY SETS}

Complex fuzzy set (CFS) is one of many possible extensions of traditional fuzzy set (FS) [5], [6]. A significant difference between a CFS and an FS is the codomain on which the membership degree is defined. In an FS, a membership degree is defined on the unit interval $[0,1]$ of real numbers; while, it is the unit disk $D_{\mathbb{C}}=\{d \mid\|d\| \leqslant 1\}$ on the complex plane in a CFS. Formally, a CFS $\tilde{A}$ on a universe of discourse $X$ is defined as

$$
\tilde{A}=\left\{\left(x, \mu_{\tilde{A}}(x)\right) \mid x \in X, \mu_{\tilde{A}}(x) \in D_{\mathbb{C}}\right\} .
$$

Because a point $z$ in $D_{\mathbb{C}}$ is alternatively expressed by the Polar coordinates as

$$
z=r_{z} e^{i \varphi_{z}}
$$

a complex fuzzy set $\tilde{A}$ is therefore commonly expressed as

$$
\tilde{A}=\left\{\left(x, r(x) \cdot e^{i \varphi(x)}\right) \mid x \in X\right\}
$$

or simply $r(x) \cdot e^{i \varphi(x)}$. Commonly $r(x)(0 \leqslant r(x) \leqslant 1)$ is called the modulus part; and $\varphi(x)$ is called the phase part. Because of the complex-valued membership degrees, a CFS is capable of modelling real-world problems which involve both uncertainty and "approximately periodic" phenomena [7].

The complex-valued membership degree in the CFS theory enhances its capability of describing complicated uncertainties and enriches the theory of the conventional FS. However, a complex-valued membership degree is hard to understand compared with the conventional real-valued membership degree. So, Tamir, et. al, presented a new interpretation of the complex-valued membership degrees from a complex fuzzy class which is embedded with the complex fuzzy set class 
operations [8]. Dick, et. al, discussed the relationships between CFS and Pythagorean fuzzy set [9].

Similar to conventional FS theory, operations are defined for CFSs. However, they are not intuitively understandable compared to those defined for conventional FSs. Ramot et al, [5], [10] defined some set-theoretical operations. These operations are mainly defined on the modulus part of the complex-valued membership degrees rather than the phase part. In order to deliver operations that better illustrate the phase part of a CFS, Zhang, et al. defined the distance and $\delta$-similarity of two CFSs considering both the modulus and the phase parts [11]. However, the modulus and phase are combined loosely. Dick presented the concept of rotational invariance and defined a complex fuzzy logic system [6] to address how to combine them closely.

\section{AgGREGATION AND RANKING OF CFSS}

In [24], Yager defined the general forms of aggregations for the Pythagorean fuzzy sets and specificly the weighted quasipower mean $A g g$ is defined as

$$
\begin{aligned}
\operatorname{Agg}( & \left.\left\{C\left(a_{i}, b_{i}\right)\right\}_{i=1}^{n},\left\{w_{i}\right\}_{i=1}^{n}\right) \\
& =\left(\left(\sum_{i=1}^{n} w_{i} a_{i}^{2}\right)^{1 / 2},\left(\sum_{i=1}^{n} w_{i} b_{i}^{2}\right)^{1 / 2}\right)
\end{aligned}
$$

where $C\left(a_{i}, b_{i}\right)$ is a Pythagorean membership satisfying $a_{i}, b_{i} \in[0,1]$ and $a_{i}^{2}+b_{i}^{2} \leqslant 1, i=1, \ldots, n$; and $\sum_{i=1}^{n} w_{i}=1$. Comparing the Pythagorean membership with the CFS, we can see that the Pythagorean membership is defined on the first quarter circle of the unit disc. Inspired by this definition, we will define the weighted quasi-power mean $A g g$ on CFS as

$$
\begin{aligned}
\operatorname{Agg} & \left(\left\{\tilde{A}\left(a_{i}, b_{i}\right)\right\}_{i=1}^{n},\left\{w_{i}\right\}_{i=1}^{n}\right) \\
& =\left(\left(\sum_{i=1}^{n} w_{i} a_{i}^{2}\right)^{1 / 2},\left(\sum_{i=1}^{n} w_{i} b_{i}^{2}\right)^{1 / 2}\right)
\end{aligned}
$$

where $a_{i}=r_{i}(x) \cos \left(\varphi_{i}(x)\right)$, and $b_{i}=r_{i}(x) \sin \left(\varphi_{i}(x)\right)$.

After defining aggregation on CFS, another issue we need to solve is how to order (rank) the aggregated result. In literatures, we can find several different methods based on various initiatives. For example, in [24], ordering aggregated result is conducted based on a mapping from a Pythagorean membership grade to a value in $[0,1]$, i.e., below binary function $F$ :

$$
F(r, \theta)=\frac{1}{2}+r\left(\frac{1}{2}-\frac{2 \theta}{\pi}\right)
$$

where $C(a, b)$ is a Pythagorean membership grade, $r^{2}=a^{2}+$ $b^{2}$ and $\theta=\arctan \left(\frac{b}{a}\right)$. However, this definition is given in the first quarter of the unit disc; it cannot be extended to the whole unit disc. Hence, we choose the following definition given in [14]: for any two CFSs $\tilde{A}$ and $\tilde{B}$,

$$
\tilde{A} \leqslant \tilde{B} \Longleftrightarrow r_{\tilde{A}} \cos \left(\theta_{\tilde{A}}\right) \leqslant r_{\tilde{B}} \cos \left(\theta_{\tilde{B}}\right) .
$$

In other words, if $\tilde{A}=\left(a_{1}, b_{1}\right)$ and $\tilde{B}=\left(a_{2}, b_{2}\right)$ then $\tilde{A} \leqslant \tilde{B}$ if and only if $a_{1} \leqslant a_{2}$.

\section{Supply Chain DOWNSTREAM STRATEGIC COST} CONTROL MEASURES

Since it was presented, CFS has been applied in many applications. Aghakhani and Dick developed learning algorithms based on the complex fuzzy logic and applied them to two time series prediction problems [12]. Furthermore, Chen, et al. presented a neuro-fuzzy system based on complex fuzzy logic which implements complex fuzzy rules and is applied to time-series forecasting problems[7]. Deshmukh, et al. designed and implemented a complex fuzzy logic system [13]. Ma, et al. discussed a method of using CFSs to predict bushfire warning indexes based on multiple weather indicators [14]. These works demonstrate the potential of CFSs in practice, particularly, for prediction problems. In supply chain downstream cost strategy evaluation, assessments on criteria have uncertainty and are with temporal or spatial features. However, research on handling them simultaneously is not sufficient. Considering the capablity of CFS for representing uncertainty and temporal feature at the same time, this paper builds a CFS-based model for cost strategy evaluation in supply chain downstream.

Cost is an important element that has direct impact on efficiency in business [15]. Cost reduction has always been the most important pathway to achieving competitive advantage [16]. Now, business need to implement strategies to manage and reduce costs not only on a short-term basis, but also in a long run for intense competitive pressures [17]. Cost control problem on cross-border E-commerce business is more prominent than the other business, because most products of it need to achieve through logistics and distribution. According to the statistic of the cross-border E-commerce business, products' cost accounts for only $10 \%$ of the total cost and the remaining $90 \%$ is spent on the process of storage, loading and unloading, transport, packaging, marketing and others. As a connecting link between manufacturing industries and customers in supply chain, E-commerce business is progressively shifting towards activities that are "intangible", are located further "downstream" and involve a high degree of interaction with the customer [18].

In the study, we focus on the evaluation of supply chain downstream strategic cost on cross-border E-commerce business and provide three strategic cost control measures based on literatures.

(1) M1: to choose the right logistics operation modes

(2) M2: to achieve value chain by entire process of supply chain management (SCM)

(3) M3: to improve facility development and information \& communication technology (ICT)

With the above three strategic cost control measures, we can evaluate supply chain strategic cost performance from different perspective. Therefore we need find the cost related criteria to evaluate each potential measure.

In many research, cost strategy evalutation used various cost data, such as operating costs [16], [20], [21], rental cost and risk cost [22], [23]. In this study, we summarise these costs in 
ten categories as criteria to evaluate the three potential strategic cost control measures. They are: rental cost $\left(c_{1}\right)$; operating cost $\left(c_{2}\right)$; safety cost $\left(c_{3}\right)$; risk cost $\left(c_{4}\right)$; value added service capacity $\left(c_{5}\right)$; timely distribution rate $\left(c_{6}\right)$; no return rate $\left(c_{7}\right)$; customer complaint rate $\left(c_{8}\right)$; information and communication technology $\left(c_{9}\right)$; facility management $\left(c_{10}\right)$.

\section{THE C-COPRAS METHOD}

In this section, we firstly overview the standard COPRAS method. Then we present an extended COPRAS method, the C-COPRAS method.

\section{A. The COPRAS method}

The COPRAS method is a widely-used multi-criteria decision making technique, which contains three main steps [25]: (1) normalises initial assessments regarding to each individual evaluation criterion; (2) calculates two optimisation indexes for each alternative based on criteria' optimisation directions (decision directions); and (3) ranks alternatives based on an overall index calculated from optimisation indexes. These steps are briefly described below.

Let $A=\left\{a_{1}, a_{2}, \ldots, a_{n}\right\}$ be a set of alternatives for a decision problem, $C=\left\{c_{1}, c_{2}, \ldots, c_{m}\right\}$ be a set of evaluation criteria and $W=\left\{w_{1}, w_{2}, \ldots, w_{m}\right\}$ be the associated weights with $C$. Suppose $X$ is the initial assessment (score) matrix

$$
X=\left(\begin{array}{ccc}
x_{11} & \cdots & x_{1 m} \\
\vdots & \ddots & \vdots \\
x_{n 1} & \cdots & x_{n m}
\end{array}\right)
$$

where $x_{i j}$ is the assessment on alternative $a_{i}$ with respect to criterion $c_{j}$. Given $X, C$ and $W$, we can use the COPRAS method to rank alternatives $a_{1}, \cdots, a_{n}$.

The normalisation step converts each score $x_{i j}$ in $X$ to a normalised score $\bar{x}_{i j}$ by

$$
\bar{x}_{i j}=\frac{x_{i j}}{\sum_{k=1}^{n} x_{k j}},
$$

$j=1,2, \ldots, m$. Then the weight of each criterion $c_{j}$ is imported into $\bar{X}$ to get a weighted score matrix $\hat{X}=\left(\hat{x}_{i j}\right)_{n \times m}$, where

$$
\hat{x}_{i j}=\bar{x}_{i j} \cdot w_{j}, \quad i=1, \ldots, n ; j=1, \ldots, m .
$$

The calculation of optimisation indexes is determined by the preferable optimisation direction of each criterion. A $c_{j}$ is associated with one of two preferable optimisation directions, i.e., positive (the bigger the better, a.k.a. "optimisation direction is maximisation") or negative (the smaller the better, a.k.a. "optimisation direction is minimisation"). Without loss of generality, let $C^{+}$be the set of criteria with positive optimisation direction and $C^{-}$be the set of criteria with negative optimisation direction, then for each alternative $a_{i} \in A$ two optimisation indexes corresponding to $C^{+}$and $C^{-}$respectively can be calculated as

$$
S_{i}^{+}=\sum_{c_{j} \in C^{+}} \hat{x}_{i j}, \quad S_{i}^{-}=\sum_{c_{j} \in C^{-}} \hat{x}_{i j}, \quad i=1,2, \ldots, n
$$

Using these two optimisation indexes, an overall ranking index $Q_{i}$ is therefore calculated for each alternative $a_{i}$ :

$$
Q_{i}=S_{i}^{+}+\frac{\sum_{k=1}^{n} S_{k}^{-}}{S_{i}^{-} \sum_{k=1}^{n} \frac{1}{S_{k}^{-}}}, \quad i=1,2, \ldots, n
$$

Finally, $Q_{i},(i=1,2, \ldots, n)$ is used to rank alternatives. A higher $Q_{i}$ means a better assessment on $a_{i}$.

In existing studies, the assessment $x_{i j}$ are often numbers or fuzzy sets. In this study, we use CFS as assessment, i.e., $x_{i j}$ are CFSs. The motivation of this process is based on the uncertain and temporal features of evaluation context, such as particular time period and imprecise expressions.

\section{B. The C-COPRAS method}

In this section, an extended COPRAS method, named CCOPRAS, is presented. The motivation of the C-COPRAS method comes from two aspects: combining the temporal and uncertain feature in assessments in criteria evaluation. Generally speaking, evaluating an alternative in terms of a criterion needs to consider a certain context with temporal or spatial features and various uncertainties.

Firstly, a normalisation method is developed to normalise assessments on a given criterion. Let $\tilde{x}_{i j}$ be the assessment on alternative $a_{i}$ in terms of criterion $c_{j}$, where $\tilde{x}_{i j}$ is a CFS, $i=1, \ldots, n$. Then we define two types of normalisations below.

Definition 5.1: Let $\Delta_{I}=\sum_{i=1}^{n}\left\|\tilde{x}_{i j}\right\|$, then the type-I normalisation of $\tilde{x}_{i j}, i=1, \ldots, n$, gives

$$
\overline{\tilde{x}}_{i j}=\frac{\tilde{x}_{i j}}{\Delta_{I}}
$$

Definition 5.2: Let $\Delta_{I I}=\left\|\sum_{i=1}^{n} \tilde{x}_{i j}\right\|$, then the type-I normalisation of $\tilde{x}_{i j}, i=1, \ldots, n$, gives

$$
\overline{\tilde{x}}_{i j}=\frac{\tilde{x}_{i j}}{\Delta_{I I}}
$$

Following Definition 5.1 and Definition 5.2, we can show that under both normlisations, the vector sum $\sum_{i=1}^{n} \overline{\tilde{x}}_{i j}$ of normalised assessments $\overline{\tilde{x}}_{i j}, i=1, \ldots, n$, is a CFS.

Secondly, the weights of criteria are introduced to generate a weighted normalied assessment after the normalisation step. Let $w_{j}$ be the weight of criterion $c_{j}, j=1, \ldots, m, w_{j} \in \mathbb{R}$ and the scalar sum $\sum_{j=1}^{m} w_{j}=1$. Then the weighted normalised assessment $\hat{\tilde{x}}_{i j}$ of $\overline{\tilde{x}}_{i j}$ is given as

$$
\hat{\tilde{x}}_{i j}=w_{j} \overline{\tilde{x}}_{i j}
$$

We can show that the vector sum $\sum_{i=1}^{n} \hat{\tilde{x}}_{i j}$ of $\hat{\tilde{x}}_{i j}, i=$ $1, \ldots, n$, is a CFS.

Thirdly, recall Eq. (12), the ranking index $Q_{i}$ is completely determined by optimisation indexes $S_{i}^{+}$and $S_{i}^{-}, i=1, \cdots, n$. In the C-COPRAS method, we will replace the scalar sums $S_{i}^{+}$and $S_{i}^{-}$by the vector sums of corresponding CFSs (i.e., weighted normalised assessments), $i=1, \cdots, n$. Based on the 
generation of $S_{i}^{+}$and $S_{i}^{-}$, we can show that both the vector sums $\sum_{i=1}^{n} S_{i}^{+}$and $\sum_{i=1}^{n} S_{i}^{-}$are CFSs.

In the standard COPRAS method, once $S_{i}^{-}, i=1, \cdots, n$, are obtained,

$$
\frac{\sum_{k=1}^{n} S_{k}^{-}}{\sum_{k=1}^{n} \frac{1}{S_{k}^{-}}}
$$

is a constant with respect to all $Q_{i}$ s. Hence, generally speaking, $Q_{i}$ can be any function $f\left(S_{i}^{+}, S_{i}^{-}\right)$of $S_{i}^{+}$and $S_{i}^{-}$such that $f$ is increasing with $S_{i}^{+}$and decreasing with $S_{i}^{-}$. Some typical forms of such $f$ are

(1) difference between $S_{i}^{+}$and $S_{i}^{-}$:

$$
f_{1}\left(S_{i}^{+}, S_{i}^{-}\right)=S_{i}^{+}-S_{i}^{-}
$$

(2) ratio between $S_{i}^{+}$and $S_{i}^{-}$:

$$
f_{2}\left(S_{i}^{+}, S_{i}^{-}\right)=\frac{S_{i}^{+}}{S_{i}^{-}}
$$

(3) positive proportion of $S_{i}^{+}$:

$$
f_{3}\left(S_{i}^{+}, S_{i}^{-}\right)=\frac{S_{i}^{+}}{S_{i}^{+}+S_{i}^{-}}
$$

Similarly, we can build more complex form of $f$ as the ranking index provided that the $f$ is increased with $S_{i}^{+}$and decreased with $S_{i}^{-}$. However, beacuse $S_{i}^{+}$and $S_{i}^{-}$in CCOPRAS method are CFSs ( i.e. complex numbers) and the order of CFSs is not completely consistent with scalar values, the same form functions $f$ may not hold the same properties with respect to $S_{i}^{+}$and $S_{i}^{-}$.

Finally, let us review the sum of $S_{i}^{+}$and $S_{i}^{-}$in the standard COPRAS method. By Eq. (10) and Eq. (11), the sum is

$$
S_{i}^{+}+S_{i}^{-}=\sum_{c_{j} \in C^{+}} \hat{x}_{i j}+\sum_{c_{j} \in C^{-}} \hat{x}_{i j}=\sum_{c_{j} \in C} \hat{x}_{i j}=\sum_{c_{j} \in C} \bar{x}_{i j} \cdot w_{j}
$$

Hence, it is the weighted sum, i.e. one of typical aggregation operators widely used in multi-criteria decision making research. Hence, we can replace it by other popular aggregation operators such as the geometric mean. In the CFS context, we need one more requirement when replace it by aggregation opertors, that is the vector sum should also be a CFS. As shown in Eq. (5), such a replacement is existing and practiable.

Based on the above discussions, the C-COPRAS method is summarised below:

Step 1 Normalise assessment matrix $X$ to normalized assessment matrix $\bar{X}$ following type-I (or type-II) normalisation method

Step 2 Generate weighted assessment matrix $\hat{X}$ by $\hat{\tilde{x}}_{i j}=\overline{\tilde{x}}_{i j}$. $w_{i j}$

Step 3 Calculate optimisation indexes for each alternative by $S^{+}=\sum_{c_{j} \in C^{+}} \bar{x}_{i j} \cdot w_{i j}$ and $S^{-}=\sum_{c_{j} \in C^{-}} \bar{x}_{i j} \cdot w_{i j}$

Step 4 Select ranking function $f$ to calculate ranking index $Q_{i}$

Step 5 Make final decision based on $Q_{i}$ and partial order given in Eq. (7).

\section{CASE STUDY}

In this section, we use the presented C-COPRAS method to evaluate three potential strategic cost control measures for a cross-boarder E-commerce business in China.

\section{A. Background}

A Chinese cross-boarder E-commerce business wants to select one of three strategic cost control measures given in Section IV to increase the whole performance in its supply chain. The company consulted a third-party consultancy to evaluate the three potential strategic cost control measures in terms of the 10 cost-related criteria given in Section IV. Regarding to each individual criterion, the consultancy defined its optimisation direction and weights for each alternative measure which are listed in Table I.

TABLE I

CRITERIA FOR STRATEGIC COST CONTROL MEASURES WITH DECISION DIRECTIONS AND PREDEFINED WEIGHTS.

\begin{tabular}{llrl}
\hline Criterion & Description & weight & Direction \\
\hline$c_{1}$ & Rental cost & 0.10 & negative \\
$c_{2}$ & Operating cost & 0.15 & negative \\
$c_{3}$ & Safety cost & 0.15 & negative \\
$c_{4}$ & Risk cost & 0.10 & negative \\
$c_{5}$ & Value added service capacity & 0.12 & positive \\
$c_{6}$ & Timely distribution rate & 0.12 & positive \\
$c_{7}$ & No return rate & 0.12 & positive \\
$c_{8}$ & Customer complaint rate & 0.12 & negative \\
$c_{9}$ & Information technology & 0.01 & positive \\
$c_{10}$ & Facility management & 0.01 & positive \\
\hline
\end{tabular}

With respected to the 10 criteria, evaluations on the three strategic cost control measures are given (see Table II) and expressed using linguistic terms listed in Table III.

TABLE II

INITIAL ASSESSMENT MATRIX IN LINGUISTIC EXPRESSION ("+" = POSITIVE, "-" = NEGATIVE).

\begin{tabular}{c|cccc}
\hline Criteria & Direction & $a_{1}$ & $a_{2}$ & $a_{3}$ \\
\hline$c_{1}$ & - & $\mathrm{VH}$ & $\mathrm{M}$ & $\mathrm{M}$ \\
$c_{2}$ & - & $\mathrm{VH}$ & $\mathrm{M}$ & $\mathrm{M}$ \\
$c_{3}$ & - & $\mathrm{H}$ & $\mathrm{L}$ & $\mathrm{L}$ \\
$c_{4}$ & - & $\mathrm{H}$ & $\mathrm{L}$ & $\mathrm{L}$ \\
$c_{5}$ & + & $\mathrm{M}$ & $\mathrm{H}$ & $\mathrm{L}$ \\
$c_{6}$ & + & $\mathrm{M}$ & $\mathrm{VH}$ & $\mathrm{M}$ \\
$c_{7}$ & + & $\mathrm{M}$ & $\mathrm{VH}$ & $\mathrm{M}$ \\
$c_{8}$ & - & $\mathrm{M}$ & $\mathrm{VH}$ & $\mathrm{M}$ \\
$c_{9}$ & + & $\mathrm{L}$ & $\mathrm{L}$ & $\mathrm{VH}$ \\
$c_{10}$ & + & $\mathrm{L}$ & $\mathrm{L}$ & $\mathrm{VH}$ \\
\hline
\end{tabular}

In order to rank the potential strategic cost control measures, we apply the C-COPRAS method. The ranking is conducted as follows:

Step 1: Normalise assessment matrix $X$ 
TABLE III

ASSESSMENTS IN CFSS

\begin{tabular}{c|cc|cc}
\hline & \multicolumn{4}{|c}{ CFS } \\
\hline Assessment & $r$ & $\phi$ & $a=r \cos (\phi)$ & $b=r \sin (\phi)$ \\
\hline Very Low (VL) & 0.1 & $4 \pi / 8$ & 0.000 & 0.100 \\
Low (L) & 0.3 & $3 \pi / 8$ & 0.115 & 0.277 \\
Medium (M) & 0.5 & $2 \pi / 8$ & 0.354 & 0.354 \\
High (H) & 0.7 & $1 \pi / 8$ & 0.647 & 0.268 \\
Very High (VH) & 0.9 & $0 \pi / 8$ & 0.900 & 0.000 \\
\hline
\end{tabular}

Let $X=\left(x_{i j}\right)_{10 \times 3}$ be the raw score matrix, i.e.

$$
\left(\begin{array}{ccc}
V H & M & M \\
V H & M & M \\
H & L & L \\
H & L & L \\
M & H & L \\
M & V H & M \\
M & V H & M \\
M & V H & M \\
L & L & V H \\
L & L & V H
\end{array}\right)
$$

In Cartesian coordinate, the matrix $X$ is written as

$$
\left(\begin{array}{ccc}
(0.900,0.000) & (0.354,0.354) & (0.354,0.354) \\
(0.900,0.000) & (0.354,0.354) & (0.354,0.354) \\
(0.647,0.268) & (0.115,0.277) & (0.115,0.277) \\
(0.647,0.268) & (0.115,0.277) & (0.115,0.277) \\
(0.354,0.354) & (0.647,0.268) & (0.115,0.277) \\
(0.354,0.354) & (0.900,0.000) & (0.354,0.354) \\
(0.354,0.354) & (0.900,0.000) & (0.354,0.354) \\
(0.354,0.354) & (0.900,0.000) & (0.354,0.354) \\
(0.115,0.277) & (0.115,0.277) & (0.900,0.000) \\
(0.115,0.277) & (0.115,0.277) & (0.900,0.000)
\end{array}\right)
$$

As discussed above, we use the type-I normalisation for illustration purpose. For $j=1, \Delta_{I}=0.9+0.5+0.5=$ 1.9. Hence, the type-I normalisation result is $(0.474,0.000)$ $\left(a_{1}\right),(0.186,0.186)\left(a_{2}\right),(0.186,0.186)\left(a_{3}\right)$. Similarly, we can calculate the normalised assessments for other criteria.
Noted that $\hat{\tilde{x}}_{i j}=\overline{\tilde{x}}_{i j} \cdot w_{i j}$, we get $\hat{X}$ as below

$$
\left(\begin{array}{ccc}
(0.047,0.000) & (0.019,0.019) & (0.019,0.019) \\
(0.071,0.000) & (0.028,0.028) & (0.028,0.028) \\
(0.075,0.031) & (0.013,0.032) & (0.013,0.032) \\
(0.050,0.021) & (0.009,0.021) & (0.009,0.021) \\
(0.028,0.028) & (0.052,0.021) & (0.009,0.022) \\
(0.022,0.022) & (0.057,0.000) & (0.022,0.022) \\
(0.022,0.022) & (0.057,0.000) & (0.022,0.022) \\
(0.022,0.022) & (0.057,0.000) & (0.022,0.022) \\
(0.001,0.002) & (0.001,0.002) & (0.006,0.000) \\
(0.001,0.002) & (0.001,0.002) & (0.006,0.000)
\end{array}\right)
$$

Step 3: Calculate optimisation indexes $S_{i}^{+}$and $S_{i}^{-}$

For each alternative, the optimisation indexes can be calculated. In this example, $C^{-}=\left\{c_{1}, c_{2}, c_{3}, c_{4}, c_{8}\right\}$ and $C^{+}=$ $\left\{c_{5}, c_{6}, c_{7}, c_{9}, c_{10}\right\}$, hence $S_{i}^{+}, S_{i}^{-}$and $Q_{i}(i=1,2,3)$ are calculated and listed in Table IV.

\section{TABLE IV}

RANKING INDEXES OF OPTIONAL STRATEGIC COST CONTROL MEASURES BASED ON DEFAULT RANKING INDEX $Q_{i}$.

\begin{tabular}{c|ccc}
\hline strategy & $S^{-}$ & $S^{+}$ & $Q$ \\
\hline$a_{1}$ & $(0.265,0.074)$ & $(0.075,0.077)$ & $(0.148,0.183)$ \\
$a_{2}$ & $(0.126,0.100)$ & $(0.167,0.025)$ & $(0.353,0.144)$ \\
$a_{3}$ & $(0.091,0.122)$ & $(0.066,0.067)$ & $(0.288,0.138)$ \\
\hline
\end{tabular}

Step 4 and Step 5: Calculate the ranking index $Q_{i}$ and rank available measures

Based on the indexes $Q_{i}$ and the order defined in Eq. (7), $a_{2}$ is the best strategy which is followed by $a_{3}$ and $a_{1}$.

If we replace $Q$ by the other three alternative indexes $f_{1}$, $f_{2}$, and $f_{3}$, we get the indexes as shown in Table V. All three alternative indexes give $a_{2}$ as the best option, then followed by $a_{3}$ and $a_{1}$.

TABLE V

RANKING INDEXES OF OPTIONAL STRATEGIC COST CONTROL MEASURES BASED ON ALTERNATIVE INDEXES.

\begin{tabular}{c|ccc}
\hline strategy & $f_{1}$ & $f_{2}$ & $f_{3}$ \\
\hline$a_{1}$ & $(-0.190,0.003)$ & $(0.338,0.196)$ & $(0.268,0.107)$ \\
$a_{2}$ & $(0.041,-0.075)$ & $(0.910,-0.524)$ & $(0.513,-0.134)$ \\
$a_{3}$ & $(-0.025,-0.055)$ & $(0.612,-0.084)$ & $(0.381,-0.032)$ \\
\hline
\end{tabular}

\section{CONCLUSION}

The global cross-border E-commerce is ballooning. The rapid development of E-commerce owes to the saving of transaction cost. Nevertheless, there is surprisingly little empirical evidence as to the impact of E-commerce on the cost of business. So, based on the analysis of characteristics of crossborder E-commerce, we explored the issue of strategic cost control in supply chain downstream. We have summarised three strategic cost control measures and evaluated them with an extended COPRAS method. Then, we facilitated the experts to evaluate alternatives with ten different criteria. At last this

Step 2: Generate weighted assessment matrix $\hat{X}$ 
in-depth case study indicates that the supply chain management to be most valuable. This is the basis for cross-border E-commerce supply chain wide application. It will enable a new level of transparency and thus a more sophisticated supply chain.

Presently, the issue of strategic cost control in combination with COPRAS is a relatively new research topic. So, this study is not free from limitations. These limitations set stage for future research.

Firstly, this study used a limited number of experts from a third-party consultancy. Future research may repeat this method using multiple experts to justify the validity of the study.

Secondly, it should be mentioned that understanding the barriers and drivers of COPRAS implementation helps Ecommerce to introduce costly effective practices. So, further research will attempt to focus on this issue.

Thirdly, this research has explored only one case study in an E-commerce supply chain. Hence conclusions may not generally suit various companies and industries. Future works should conduct research related to investigation on Ecommerce practices and performances in different sectors.

\section{ACKNOWLEDGMENT}

The authors would like to acknowledge financial supports of the major cultivating project on Chongqing University of Arts and Sciences , and the Social Science Planning Project of Chongqing (2014BS105).

\section{REFERENCES}

[1] A. Accenture, "Global cross border e-commerce market 2020," June 2016.

[2] P. Jain, K. Jain, and P. Jain, "E-commerce and its global impact," Innovare Journal of Engineering \& Technology, vol. 2, pp. 1-5, 2016.

[3] D. Röser, B. Mola-Yudego, L. Sikanen, R. Prinz, D. Gritten, B. Emer, K. Väätäinen, and A. Erkkilä, "Natural drying treatments during seasonal storage of wood for bioenergy in different European locations," Biomass Bioenergy, vol. 35, no. 10, pp. 4238-4247, 2011.

[4] F. Arikan, "An interactive solution approach for multiple objective supplier selection problem with fuzzy parameters," Journal of Intelligent Manufacturing, vol. 26, no. 5, pp. 989-998, 2015.

[5] D. Ramot, M. Friedman, G. Langholz, and A. Kandel, "Complex fuzzy logic," IEEE Transactions on Fuzzy Systems, vol. 11, no. 4, pp. 450-461, 2003.

[6] S. Dick, "Toward complex fuzzy logic," IEEE Transactions on Fuzzy Systems, vol. 13, no. 3, pp. 405-414, 2005.

[7] Z. Chen, S. Aghakhani, J. Man, and S. Dick, "ANCFIS: a neurofuzzy architecture employing complex fuzzy sets," IEEE Transactions on Fuzzy Systems, vol. 19, no. 2, pp. 305-322, 2011.

[8] D. E. Tamir, L. Jin, and A. Kandel, "A new interpretation of complex membership grade," International Journal of Intelligent Systems, vol. 26, pp. 285-312, 2011.

[9] S. Dick, R. R. Yager, and O. Yazdanbakhsh, "On Pythagorean and complex fuzzy set operations," IEEE Transactions on Fuzzy Systems, vol. 24, no. 5, pp. 1009 - 1021, 2016.

[10] D. Ramot, R. Milo, M. Friedman, and A. Kandel, "Complex fuzzy sets," IEEE Transactions on Fuzzy Systems, vol. 10, no. 2, pp. 171-186, 2002.

[11] G. Zhang, T. S. Dillon, K. Cai, J. Ma, and J. Lu, "Operation properties and $\delta$-equalities of complex fuzzy sets," International Journal of Approximate Reasoning, vol. 50, no. 8, pp. 1227-1249, 2009.

[12] S. Aghakhani and S. Dick, "An on-line learning algorithm for complex fuzzy logic," in IEEE International Conference on Fuzzy Systems (FUZZ), July 2010, pp. 1-7.
[13] A. Y. Deshmukh, A. B. Bavaskar, R. R. Bajaj, and A. G. Keskar, "Implementation of complex fuzzy logic modules with VLSI approach," International Journal of Computer Science and Network Security, vol. 8, no. 9, pp. 172-178, 2008.

[14] J. Ma, G. Zhang, and J. Lu, "A method for multiple periodic factor prediction problems using complex fuzzy sets," IEEE Transactions on Fuzzy Systems, vol. 20, no. 1, 2012, 32-45.

[15] F. Rezaei, F. Alilou, and N. Naraghi, "Determining effective elements on participation in a b2b e-commerce system by considering time and cost," Journal of Automation and Control Engineering, vol. 1, no. 4, pp. 332-335, 2013.

[16] L.-C. Wu, "Supplier selection under uncertainty: a switching options perspective," Industrial Management \& Data Systems, vol. 109, no. 2, pp. 191-205, 2009.

[17] S. P. Nimocks, R. L. Rosiello, and O. Wright, "Managing overhead costs," The McKinsey Quarterly, vol. 2, pp. 106-117, 2005.

[18] C. Homburg, H. Wilczek, and A. Hahn, "Looking beyond the horizon: How to approach the customers' customers in business-to-business markets," Journal of Marketing, vol. 78, no. 5, pp. 58-77, 2014.

[19] T. Skjøtt-Larsen, P. B. Schary, J. H. Mikkola, and H. Kotzab, Managing the Global Supply Chain, 3rd ed. Liber, Copenhagen: Copenhagen Business School Press, 2007.

[20] W. H. Delone and E. R. McLean, "Measuring e-commerce success: applying the delone \& mclean information systems success model," International Journal of Electronic Commerce, vol. 9, no. 1, pp. 3147, 2004.

[21] A. I. Pettersson and A. Segerstedt, "Measuring supply chain cost," International Journal of Production Economics, vol. 143, no. 2, pp. 357-363, 2013.

[22] A. Kaklauskas, E. K. Zavadskas, S. Raslanas, R. Ginevicius, A. Komka and P. Malinauskas, "Selection of low-e windows in retrofit of public buildings by applying multiple criteria method COPRAS: A Lithuanian case," Energy and Buildings, vol. 38, no. 5, pp. 454-462, 2006.

[23] J. Eliasson and M. Lundberg, "Do CostBenefit Analyses Influence Transport Investment Decisions? Experiences from the Swedish Transport Investment Plan 2010-21," Transport Reviews, vol. 32, no. 1, pp. 29-48, 2012.

[24] R. R. Yager and A. M. Abbasov, "Pythagorean membership grades, complex numbers, and decision making," International Journal of Intelligent Systems, vol. 28, pp. 436 - 452, 2013.

[25] E. K. Zavadskas, A. Kaklauskas, Z. Turskis, and J. Tamošaitiene, "Multi-attribute decision-making model by applying grey numbers," Informatica, vol. 20, no. 2, pp. 305-320, 2009.

[26] S. Roychowdhury and W. Pedrycz, "A survey of defuzzification strategies," International Journal of Intelligent Systems, vol. 16, no. 6, pp. 679-695, 2001 